Article

\title{
Determination of Particle Size and Distribution through Image-Based Macroscopic Analysis of the Structure of Biomass Briquettes
}

\author{
Veronika Chaloupková ${ }^{1}$, Tatiana Ivanova ${ }^{1, * \mathbb{D}}$, Ondřej Ekrt ${ }^{2}$, Abraham Kabutey ${ }^{3}$ \\ and David Herák ${ }^{3}$ \\ 1 Department of Sustainable Technologies, Faculty of Tropical AgriSciences, \\ Czech University of Life Sciences Prague, Kamýcká 129, 16521 Prague 6-Suchdol, Czech Republic; \\ vchaloupkova@ftz.czu.cz \\ 2 Department of Physics and Measurements, Faculty of Chemical Engineering, \\ University of Chemistry and Technology Prague, Technická 5, 16628 Prague 6-Dejvice, Czech Republic; \\ ondrej.ekrt@vscht.cz \\ 3 Department of Mechanical Engineering, Faculty of Engineering, Czech University of Life Sciences Prague, \\ Kamýcká 129, 16521 Prague 6-Suchdol, Czech Republic; kabutey@tf.czu.cz (A.K.); herak@tf.czu.cz (D.H.) \\ * Correspondence: ivanova@ftz.czu.cz; Tel.: +420-224-382-603
}

Received: 20 December 2017; Accepted: 23 January 2018; Published: 2 February 2018

\begin{abstract}
Via image-based macroscopic, analysis of a briquettes' surface structure, particle size, and distribution was determined to better understand the behavioural pattern of input material during agglomeration in the pressing chamber of a briquetting machine. The briquettes, made of miscanthus, industrial hemp and pine sawdust were produced by a hydraulic piston press. Their structure was visualized by a stereomicroscope equipped with a digital camera and software for image analysis and data measurements. In total, 90 images of surface structure were obtained and quantitatively analysed. Using Nikon Instruments Software (NIS)-Elements software, the length and area of 900 particles were measured and statistically tested to compare the size of the particles at different surface locations. Results showed statistically significant differences in particles' size distribution: larger particles were generally on the front side of briquettes and vice versa, smaller particles were on the rear side. As well, larger particles were centred in the middle of cross sections and the smaller particles were centred on the bottom of the briquette.
\end{abstract}

Keywords: compaction; computer vision; macrostructure; particle size classification; solid biofuel

\section{Introduction}

Nowadays, there is increasing interest in biofuels made of different types of biomass, including agricultural organic wastes and energy crops as an alternative, renewable and potentially sustainable energy source compared to conventional fossil fuels [1-5]. Production of high-quality biofuels with good mechanical, chemical and energy properties is strongly desired [6]. Appropriate design of machines, equipment and necessary infrastructure for production, handling, transport and storage of these products is required, as well, there is a general need for better and more comprehensive knowledge of the biomass material properties [7].

Briquetting, one of the densification technologies, is a fundamental and promising method for conversion of the waste and purposely grown biomass into solid biofuels [8]. It is achieved by forcing loose particles together into a larger, more compact and shaped form, by application of mechanical force to create particle-to-particle bonding $[9,10]$. Effectiveness of the densification process is given by the quality of these inter-particle bonds [11]. Generally, binding mechanisms, i.e., physical and 
chemical effects causing adhesion and bonding between solid particles, are described according to the classical theory of agglomeration by Pietsch [12]. In the case of densified biomass, binding mechanisms were reviewed by Kaliyan and Morey [11] and studied by the same authors [9] on corn stover and switchgrass briquettes and pellets using several microscope technologies, by Stelte et al. [13] on beech, spruce and straw pellets via scanning electron microscopy (SEM) or by Zhang and Guo [4] on Caragana korshinskii Kom briquettes using SEM as well. One of the factors highly affecting the strength of particle-to-particle bonds is particle size $[6,8,10,12,14,15]$. Biomass materials are characterized by a diverse range of sizes and shapes of particles [16].

Particle size and particle size distribution (PSD) are counted among the major factors determining physical and mechanical properties of briquettes as well as other solid agglomerates and particulate materials, and provide substantive information about the quality and performance of these products $[4,11,12,17,18]$. They play important roles in the flow ability, bulk density, compressibility, mechanical strength and durability of densified products. Their impact on the main physical mechanical properties of solid biofuels has been studied by many authors. Ndindeng et al. [6] studied the hardness of rice-husk briquettes, Mani et al. [19] dealt with the density of pellets made of wheat straw, barley straw, corn stover and switchgrass, Mitchual et al. [20] researched the relaxed density and compressive strength of briquettes produced from sawdust of tropical hardwoods, and Zhang and Guo [4] observed properties like density, durability, compressive strength and impact resistance of Caragana korshinskii Kom briquettes. Harun and Afzal [21] studied the density and intrinsic yield stress of pellets made of agricultural and wood biomass blends, and Missagia et al. [15] reported the durability of the rice husk pellets. In general, a finer grinding means a higher density, hardness and durability, however, it also results in higher production costs [6,11]. Apart from physical and mechanical properties, particle size has an influence on burning characteristics as well [22]. An effect of the particle size on biofuel ignition and burning rate was studied, besides others, by Davies and Abolude [23] on water hyacinth briquettes, Sutrisno et al. [22] on manghasleaf briquettes, and Saptoadi [24] on wood sawdust and rice-husk briquettes. Generally, reduced particle size causes an increase in burning time, a decrease in combustion rate, but prolonged ignition time [23]. Regarding the amount of heat released during combustion, Tembe et al. [25] and Huko et al. [26] reported no significant difference in calorific values of sawdust briquettes made of different particle sizes.

One of the methods by which particle size, as well as other properties of solid biofuels can be observed nowadays is with computer/machine vision and image analysis. It is a highly useful and effective technique with a versatile range of applications in various areas of industry and science [27-29]. Typically, it is used to increase the efficiency and quality of controlled products, thus, it is characterized by a focus on typical tasks associated with managing the production process, including the visual inspection of prescribed visible parameters [30], identification of size, shape [31], colour [32-35], structure and texture [36], object counting [37], finding defects [38,39], and reading and verification of texts and codes [40].

Development of the machine vision and image analysis is still on the rise and its applications have slowly expanded to the research of biomass materials for energy fuel production. Generally, in the case of particulate materials it represents another approach for size and shape analysis of particles. In most of the studies published so far, image-based analysis has been primarily used for identifying particle size and its distribution from loose aggregate samples $[16,18,41-48]$ before they are utilized in concrete mixtures, in place of directly measurements from the image of compact cross sections [49]. Further, it can be used for observation of surface and/or interior structures of agglomerates [12,49-52]. In the case of solid biofuels, it was used by Zhang and Guo [4], Kaliyan and Morey [9], Stelte et al. [13] and Muntean et al. [53].

Knowledge of the agglomeration process of a raw input material during the pressing process is critical in understanding the briquetting process, as well as controlling the manufacturing operation. It can help to improve modes, parameters and the technological conditions of equipment for 
briquettes production, and above all, may ensure the required high-quality biofuels with appropriate technological and mechanical properties, according to the given standards.

The aim of the present paper is to analyse the macrostructure of briquettes made from different sources of biomass materials, namely miscanthus, industrial hemp and pine sawdust, through microscope technology equipped with a digital camera and special software for image analysis and data measurement, in order to determine particles' size and their surface distribution and to observe if there are any principles and rules in the behaviour and interaction between particles at different locations on the briquette surface within different sources of biomass, and thus, to better understand the behavioural patterns of an input material in the pressing chamber of the briquetting machine.

\section{Materials and Methods}

Briquettes made of the three following biomass materials (Figure 1) were analysed: miscanthus (Miscanthus $\times$ giganteus), a promising energy crop [54]; industrial hemp (Cannabis sativa L.), an annual fiberous plant, which utilized for energy purposes is an interesting alternative $[1,55]$; and for comparison pine sawdust (Pinus L.), a wood material representing traditional feedstock for solid biofuels production [56].
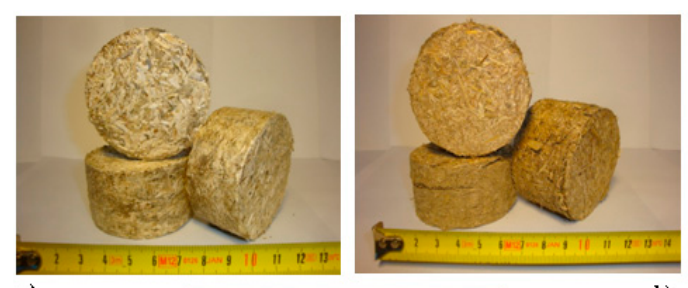

a)

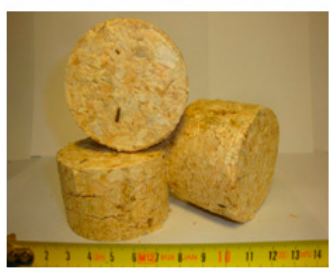

b)

c)

Figure 1. Produced briquettes made of different biomass sources: (a) hemp; (b) miscanthus; (c) pine sawdust.

The moisture content (w.b.) of the miscanthus, hemp and pine sawdust before briquetting was $9.91 \%, 8.82 \%$, and $10.35 \%$, respectively. All dry materials were grinded by a hammer mill (9FQ-40C, Pest Control Corporation, s.r.o., Vlčnov, Czech Republic) with a screen hole diameter of $12 \mathrm{~mm}$. The PSD of the input materials, determined by an oscillating screen method [57] using a horizontal sieve shaker (AS 200, Retsch, Haan, Germany) with seven sieves of apertures 0.63, 1.5, 3.15, 4.5, 6.7, 8 and $10 \mathrm{~mm}$, and 30-min sieve shaking time and amplitude $3.0 \mathrm{~mm} /$ " $\mathrm{g}$ ", is presented in Table 1 and Figure 2.

Table 1. Particle size distribution (PSD) of examined materials.

\begin{tabular}{cccccccc}
\hline \multicolumn{7}{c}{ Material Retained on Sieve } \\
\hline Sieve Opening Size & \multicolumn{2}{c}{ Miscanthus } & \multicolumn{2}{c}{ Hemp } & \multicolumn{2}{c}{ Pine Sawdust } \\
\hline $\mathbf{( m m )}$ & $\mathbf{( g )}$ & $\mathbf{\%}$ & $\mathbf{( g )}$ & $\mathbf{\%}$ & $\mathbf{( g )}$ & $\mathbf{\%}$ \\
\hline 10 & 0.01 & 0.02 & 23.11 & 56.16 & 4.22 & 5.08 \\
8 & 0.06 & 0.09 & 0.00 & 0.00 & 4.96 & 5.98 \\
6.7 & 0.10 & 0.15 & 0.00 & 0.00 & 7.79 & 9.39 \\
4.5 & 0.69 & 1.04 & 0.06 & 0.15 & 14.14 & 17.04 \\
3.15 & 2.73 & 4.12 & 0.60 & 1.46 & 11.90 & 14.34 \\
1.5 & 33.80 & 51.00 & 7.53 & 18.30 & 20.50 & 24.70 \\
0.63 & 16.44 & 24.81 & 5.38 & 13.07 & 9.59 & 11.55 \\
$<0.63$ & 12.44 & 18.77 & 4.47 & 10.86 & 9.90 & 11.93 \\
Total & 66.27 & 100.00 & 41.15 & 100.00 & 83.00 & 100.00 \\
\hline
\end{tabular}


The PSD of pine sawdust material was quite uniform. Owing to the particles' spherical shape, the decreased screen opening size corresponded to the decreased particle size. Most material (almost 25\%) was kept by the sieve with $1.5 \mathrm{~mm}$ openings. Sieve analysis of hemp and miscanthus did not give reliable outputs on their real PSD, in the case of hemp this was caused by its fibrous nature and the parallelepiped shape of its non-fibre particles; more than half of the mass was caught by the screen with the largest apertures. In the case of the miscanthus material, it was due to the needle-like shape of its particles as the standard procedure does not obviate the "falling-through" effect of longer particles through smaller sieve openings $[42,43,58]$. For this reason more than $75 \%$ of the material was retained on the last two screens with the smallest openings (1.5 and $0.63 \mathrm{~mm}$ ).

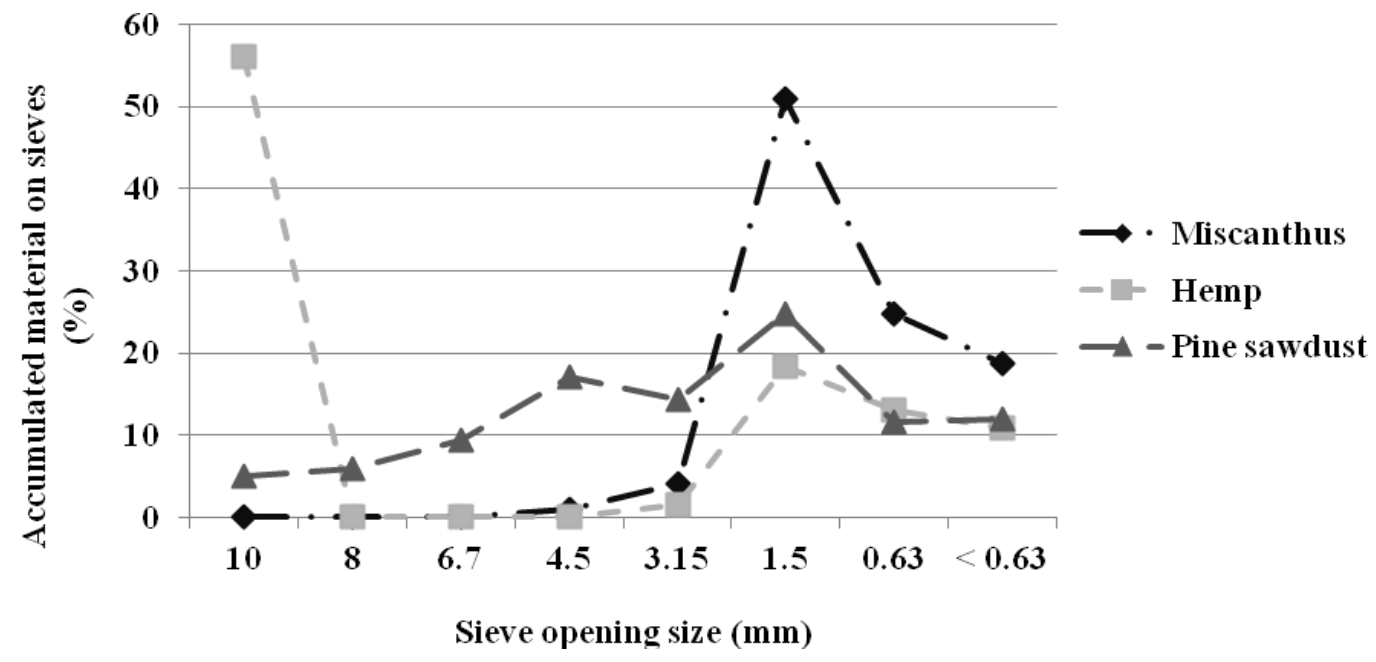

Figure 2. Comparison of particle size distribution (PSD) of studied materials.

Dry and grinded materials were pressed to the form of fuel briquettes (Figure 1) by hydraulic piston briquetting machine (BrikStar CS 50, Briklis, Malšice, Czech Republic) (Figure 3) with a $65 \mathrm{~mm}$ diameter pressing cylinder, which approximately corresponds to the diameter of the produced briquettes with the length of the briquettes ranging from 30 to $50 \mathrm{~mm}$ (Table 2). The briquetting press works under maximum compression pressure of $18 \mathrm{MPa}$ and pressing temperature $60^{\circ} \mathrm{C}$ [59]. Briquettes were produced without any additional binding agents (additives) at room temperature. In the middle of the compacting process, when stronger briquettes were produced, 5 non-consecutive briquettes from each material were selected for further analysis (Table 2).

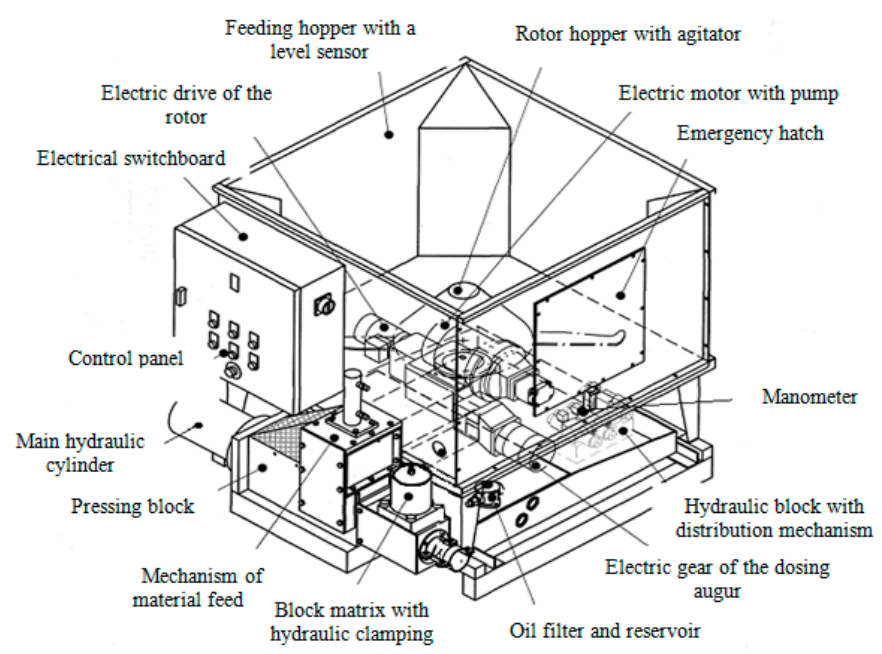

Figure 3. Diagram of hydraulic piston briquetting press BrikStar CS 50. 
Table 2. The length and diameter of selected briquettes.

\begin{tabular}{ccccccc}
\hline \multirow{2}{*}{ No. of Briquette } & \multicolumn{2}{c}{ Hemp } & \multicolumn{2}{c}{ Miscanthus } & \multicolumn{2}{c}{ Pine Sawdust } \\
\cline { 2 - 7 } & $\begin{array}{c}\text { Length } \\
(\mathbf{m m})\end{array}$ & $\begin{array}{c}\text { Diameter } \\
\mathbf{( m m )}\end{array}$ & $\begin{array}{c}\text { Length } \\
\mathbf{( m m )}\end{array}$ & $\begin{array}{c}\text { Diameter } \\
\mathbf{( m m})\end{array}$ & $\begin{array}{c}\text { Length } \\
(\mathbf{m m})\end{array}$ & $\begin{array}{c}\text { Diameter } \\
(\mathbf{m m})\end{array}$ \\
\hline 1 & 30.28 & 66.54 & 48.13 & 68.38 & 46.32 & 68.09 \\
2 & 34.09 & 66.92 & 53.91 & 69.55 & 48.92 & 67.77 \\
3 & 43.37 & 66.73 & 49.33 & 68.97 & 43.07 & 67.81 \\
4 & 40.06 & 67.02 & 45.87 & 68.54 & 44.60 & 67.76 \\
5 & 33.26 & 67.07 & 37.83 & 68.34 & 48.20 & 67.78 \\
Arithmetic mean & 36.21 & 66.86 & 47.01 & 68.76 & 46.22 & 67.84 \\
\pm Standard deviation & \pm 5.35 & \pm 0.22 & \pm 5.91 & \pm 0.51 & \pm 2.44 & \pm 0.14 \\
\hline
\end{tabular}

Using a stereomicroscope (Stemi 2000, Carl Zeiss, Jena, Germany) equipped with illumination (VisiLED MC1500, Schott, Mainz, Germany), the selected briquettes were observed with 6.5 times magnification and scanned by the digital camera (DFW-SX 910, Sony Corp., Minato, Tokyo, Japan) with charge-coupled device (CCD) detector of resolution $1392 \times 1040$ pixels through IC Capture 2.3 image acquisition software (The Imaging Source Europe $\mathrm{GmbH}$, Bremen, Germany) (Figure 4). Briquettes were scanned at 6 specific points/locations on the briquette cross sections (Figure 5).

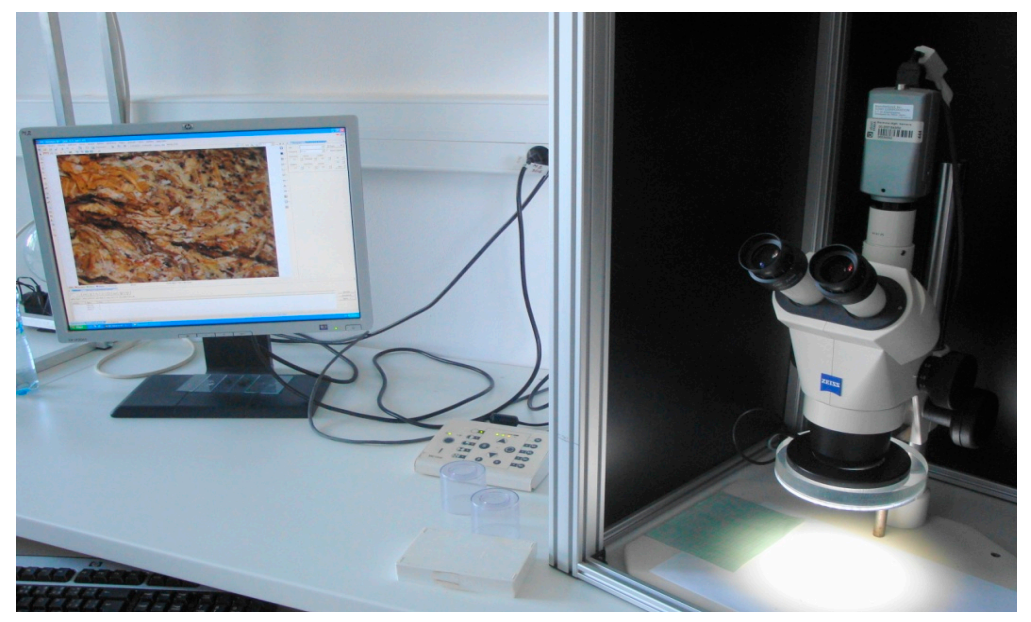

Figure 4. Equipment for macroscopic image analysis.

a)

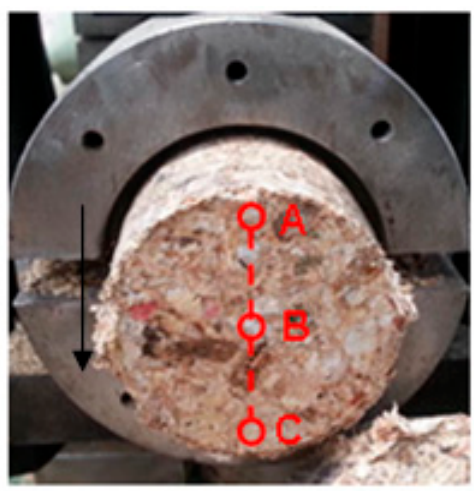

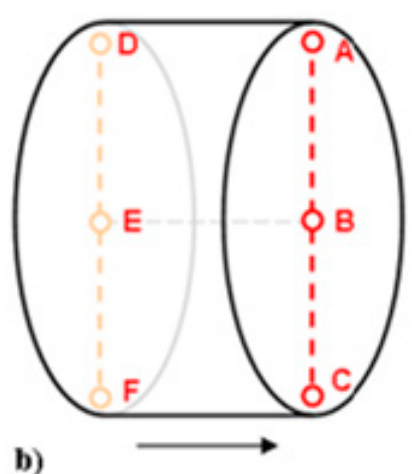

b)

Figure 5. The scheme of analysed point, (a) position of briquette leaving from press die; (b) points A-C placed on the front side of the briquettes; D-F on the rear side.

The points A-C were placed on the front side, points D-F on the rear side, where the piston presses during the briquetting. From each briquette six images were taken, in total 90 images. The acquired 
images were subsequently processed and quantitatively analysed with the NIS-Elements Advanced Research 3.2 (Laboratory Imaging s.r.o., Prague, Czech Republic), special software for image analysis. The quantitative measurements of particle size in terms of length and area were carried out on the outer surface points A-F (Figure 5).

To compare the behavioural pattern of the surface locations (points A-F), 50 measurements of particle lengths and areas were done for each point (Figure 6), in total 900 measurements of particle lengths and areas for all of the materials.

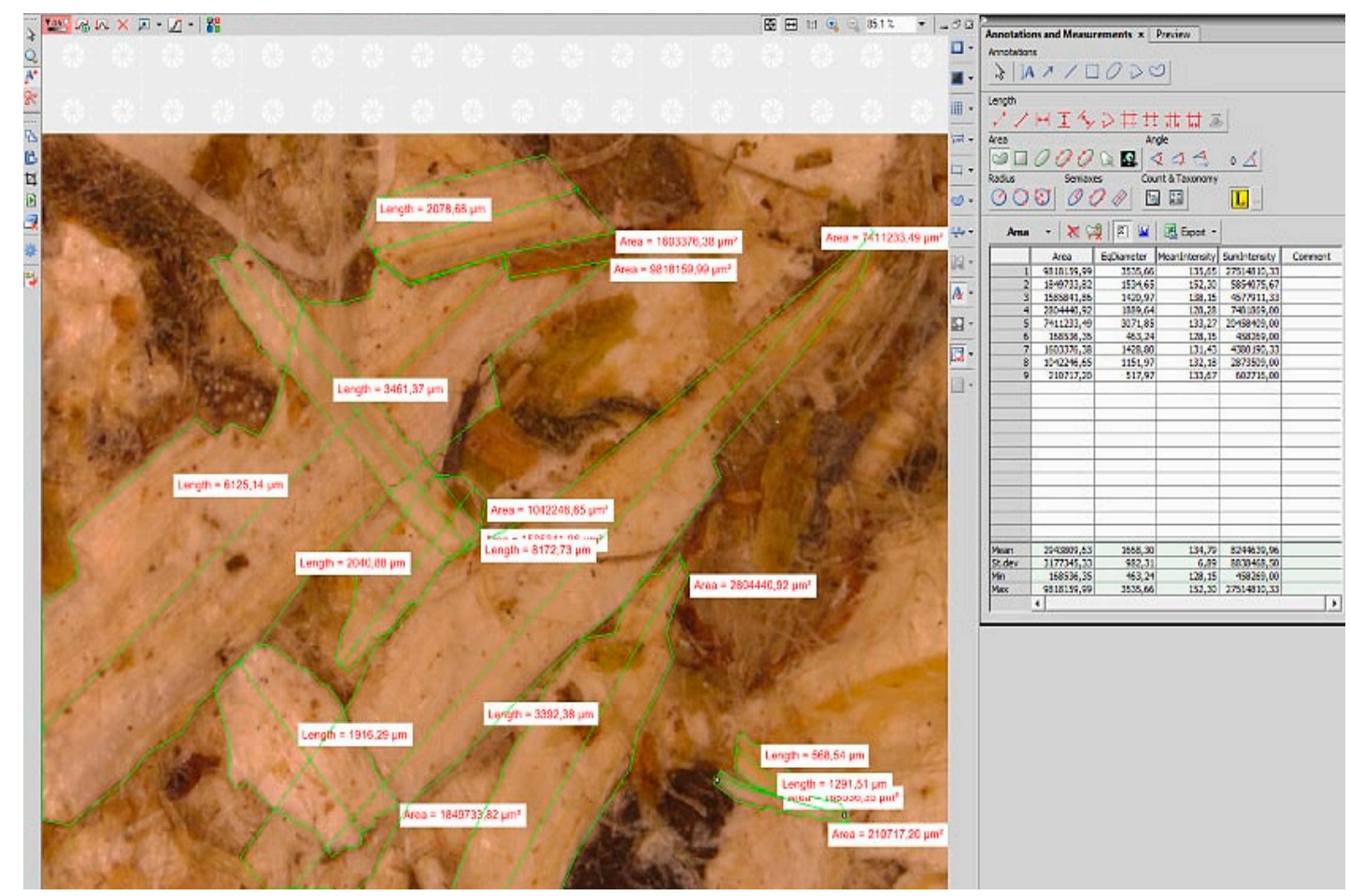

Figure 6. Size measurement of hemp briquette's particles via NIS-Elements AR software (Version 2.3, Laboratory Imaging s.r.o., Prague, Czech Republic).

It was also intended to observe the inside structure of the briquettes. The briquettes were cut by an electric band saw (PractiX 285.230 G, Bomar, Brno, Czech Republic) into two equal halves, i.e., two equal cylinders were created from each briquette. On the inner side of one cut half, the three points were scanned and observed as was done on the exterior surface, specifically, two points remotely placed $5 \mathrm{~mm}$ from the briquette edges (top and bottom) and one point in the middle of the circular cross section. Images of these points were taken, however, it was not possible to quantitatively analyse the structure since there were no clearly defined particles for measurements.

The measured data were analysed using Statistica 12 software (Version 12, TIBCO Software Inc., Palo Alto, CA, USA) by descriptive statistics (arithmetic means, medians, minimum and maximum values, etc.) to summarize the measured data sample and by statistical hypothesis testing to compare the scanned locations on the briquette surface structure in terms of particle size.

With respect to the objective of the paper-to prove a statistically significant difference in the length and area of particles at 6 specified points and to identify where the particles are longest and have the biggest area and vice versa, the shortest and with the smallest area, a one-way ANOVA test was intended to be used. It is commonly applied for comparison of three or more dependent samples of equal or different sample sizes [60]. Before the statistical testing, the data were checked (based on the outputs of descriptive statistics) for normality via Shapiro-Wilk's, Kolmogorov-Smirnov and Lilliefors tests, which is an assumption for usage of the above mentioned ANOVA test. Based on a 
set significance level (0.05) and calculated $p$-values the normality tests rejected the assumption that the data has normal distribution; for this reason, a non-parametric equivalent of the one-way ANOVA test i.e., Kruskal-Wallis test with a significance level 0.05 was used. Even though non-parametric tests are less powerful than parametric ones [60], in this case as it is presented, the test provided results with more than $99 \%$ confidence level. In order to make the testing complete, the statistical processing included the post hoc Mann-Whitney U tests to determine where the differences lie between the tested groups (scanned points). The obtained results were finally tabulated and plotted.

\section{Results}

To compare the behavioural pattern in briquettes' surface structure, 900 values of particle size, i.e., lengths and areas, were measured at different surface locations (namely points A-F). Descriptive statistics summarizing these measured values $\left(\right.$ in $\mathrm{mm} / \mathrm{mm}^{2}$ ) and sorted out according to the scanned locations are presented in Table 3.

Table 3. Descriptive statistics of studied points on briquettes' surface (in $\mathrm{mm} / \mathrm{mm}^{2}$ ).

\begin{tabular}{ccccccccc}
\hline Location & Measured Quantity & $\mathbf{N}$ & Mean & Median & Min & Max & Std. Dev & Variance \\
\hline \multirow{2}{*}{ A } & Area & 150 & 3.15 & 1.89 & 0.18 & 14.34 & 3.00 & $9.02 \times 10^{6}$ \\
& Length & 150 & 2.75 & 2.39 & 0.58 & 8.72 & 1.71 & 2927.18 \\
\hline \multirow{2}{*}{ B } & Area & 150 & 3.63 & 2.55 & 0.08 & 25.62 & 3.66 & $1.34 \times 10^{7}$ \\
& Length & 150 & 3.09 & 2.60 & 0.57 & 8.69 & 1.77 & $3.12 \times 10^{3}$ \\
\hline \multirow{2}{*}{ C } & Area & 150 & 2.42 & 1.60 & 0.13 & 14.43 & 2.45 & $6.02 \times 10^{6}$ \\
& Length & 150 & 2.59 & 2.06 & 0.57 & 8.91 & 1.75 & $3.05 \times 10^{3}$ \\
\hline \multirow{2}{*}{ D } & Area & 150 & 2.20 & 1.04 & 0.04 & 22.98 & 3.45 & $1.19 \times 10^{7}$ \\
& Length & 150 & 2.38 & 1.68 & 0.27 & 9.48 & 1.90 & $3.61 \times 10^{3}$ \\
\hline \multirow{2}{*}{ E } & Area & 150 & 2.82 & 1.41 & 0.08 & 22.05 & 3.30 & $1.09 \times 10^{7}$ \\
& Length & 150 & 2.59 & 1.99 & 0.30 & 9.04 & 1.88 & $3.53 \times 10^{3}$ \\
\hline \multirow{2}{*}{ F } & Area & 150 & 1.59 & 0.77 & 0.08 & 14.39 & 2.11 & $4.47 \times 10^{6}$ \\
& Length & 150 & 2.01 & 1.44 & 0.37 & 6.76 & 1.44 & $2.07 \times 10^{3}$ \\
\hline
\end{tabular}

From the values of the mean and median it is evident that larger particles are located at the front side of the briquettes (points A-C). It can be seen that grinded particles have a wide size range and associated relatively high variances, which indicates that the measured data within set points are very spread out around the mean and from each other (these results indicate that the measured data did not come from a normal distribution).

Comparisons of the particles' size among scanned surface location tested by the Kruskal-Wallis test are presented in Tables 4 and 5. The same results are graphically expressed by box plots (Figures 7 and 8).

Table 4. Kruskal-Wallis test results for length variable.

\begin{tabular}{ccccc}
\hline Dependent Length & Code & N & Sum of Ranks & Mean Rank \\
\hline A & 1 & 150 & $74,122.00$ & 494.1467 \\
B & 2 & 150 & $81,877.50$ & 545.8500 \\
C & 3 & 150 & $68,477.00$ & 456.5133 \\
D & 4 & 150 & $60,374.00$ & 402.4933 \\
E & 5 & 150 & $66,472.50$ & 443.1500 \\
F & 6 & 150 & $54,127.00$ & 360.8467 \\
\multicolumn{5}{c}{ Kruskal-Wallis test: H (5, N = 900) = 47.56759, $p=0.0000$} \\
\hline
\end{tabular}


Table 5. Kruskal-Wallis test for area variable.

\begin{tabular}{ccccc}
\hline Dependent Area & Code & N & Sum of Ranks & Mean Rank \\
\hline A & 1 & 150 & $77,625.00$ & 517.5000 \\
B & 2 & 150 & $84,355.00$ & 562.3667 \\
C & 3 & 150 & $69,373.00$ & 462.4867 \\
D & 4 & 150 & $55,087.00$ & 367.2467 \\
E & 5 & 150 & $69,595.00$ & 463.9667 \\
F & 6 & 150 & $49,415.00$ & 329.4333 \\
\multicolumn{4}{c}{ Kruskal-Wallis test: H (5, N = 900) = 86.38499, $p=0.0000$} \\
\hline
\end{tabular}

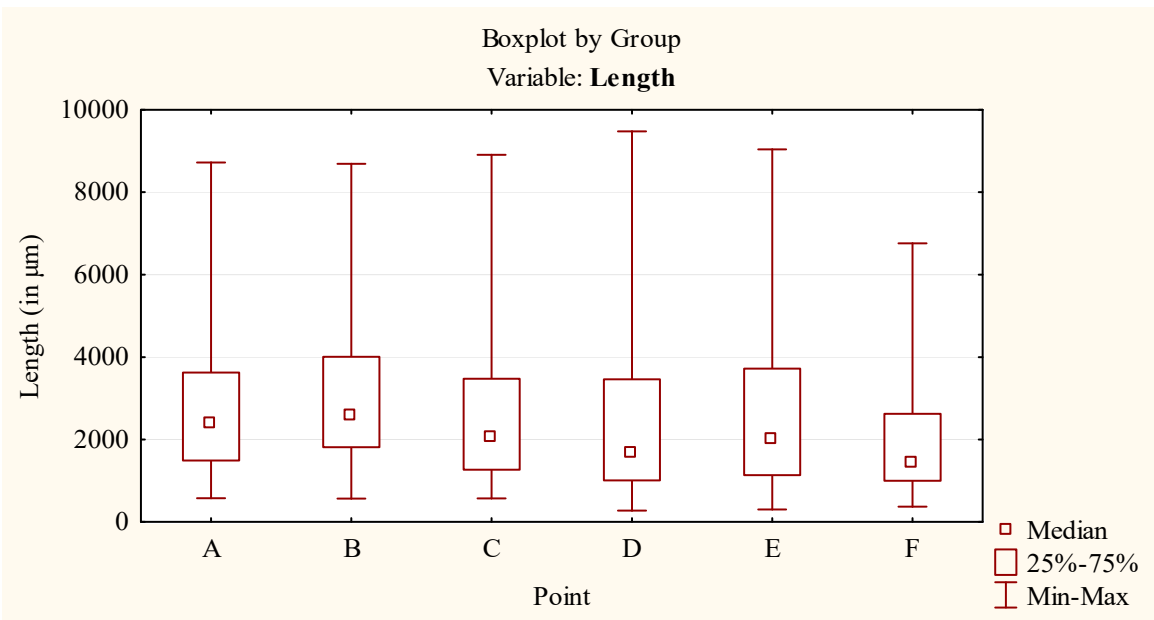

Figure 7. Group box plot for length variable (in $\mu \mathrm{m}$ ).

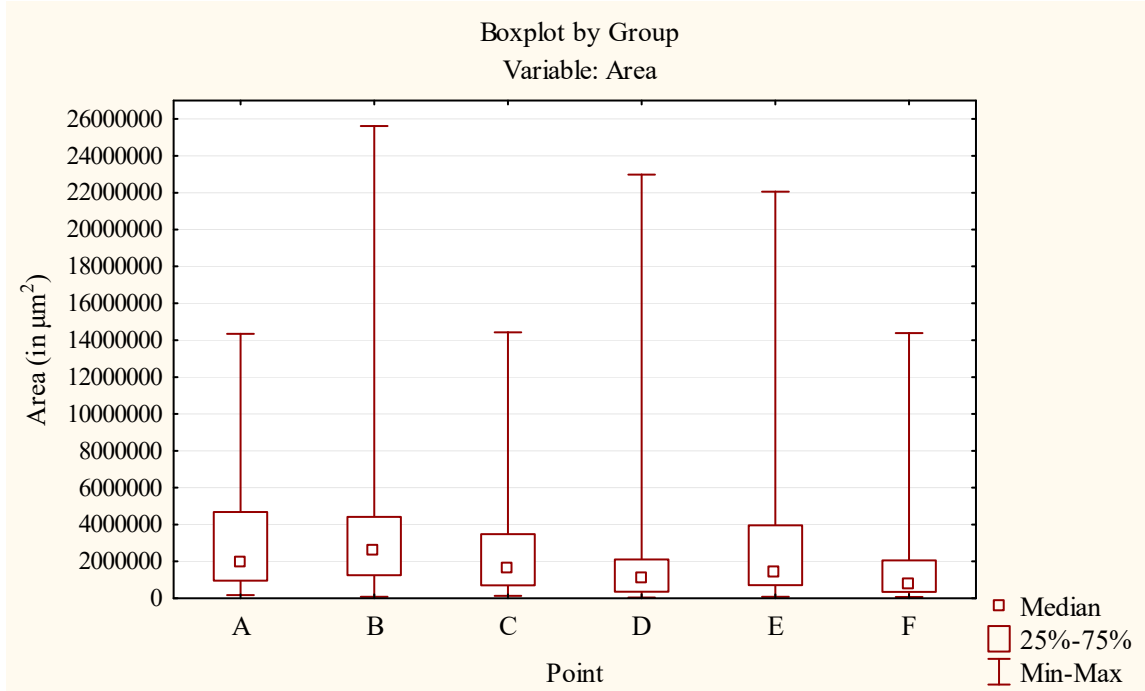

Figure 8. Group box plot for area variable (in $\left.\mu \mathrm{m}^{2}\right)$.

Based on the achieved significance level of the Kruskal-Wallis test $(p=0.0000)$, a statistically significant difference (with more than $99 \%$ confidence) in the length and area of particles at specified points was demonstrated. From the sum of the ranks for the particular groups it is evident that the length of particles are largest at point B, followed by points A, C, E, D, and F. 
In general, larger particles were located on the front side, contrarily, the smaller ones were located on the rear side of the briquettes. From the sum of the rank values for the particular groups (points) it is evident that the areas of the largest particles are at point $\mathrm{B}$, followed by points $\mathrm{A}, \mathrm{E}, \mathrm{C}, \mathrm{D}$, and $\mathrm{F}$.

To complete the testing, multiple comparison tests were done and the following Tables 6-9 show where the significant differences (highlighted values) between the scanned points occur. Tables 6 and 8 show $z$-values (standard scores) for each comparison between points, Tables 7 and 9 show $p$-values associated with each comparison.

Table 6. Multiple comparisons $z^{\prime}$-values of area values for point variable.

\begin{tabular}{ccccccc}
\hline \multirow{2}{*}{ Dependent Area } & A & B & C & D & E & F \\
& R: $\mathbf{5 1 7 . 5 0}$ & R: $\mathbf{5 6 2 . 3 7}$ & R: $\mathbf{4 6 2 . 4 9}$ & R: $\mathbf{3 6 7 . 2 5}$ & R: $\mathbf{4 6 3 . 9 7}$ & R: $\mathbf{3 2 9 . 4 3}$ \\
\hline A & - & 1.494725 & 1.832760 & 5.005664 & 1.783454 & 6.265409 \\
B & 1.494725 & - & 3.327485 & 6.500390 & 3.278179 & 7.760134 \\
C & 1.832760 & 3.327485 & - & 3.172904 & 0.049306 & 4.432649 \\
D & 5.005664 & 6.500390 & 3.172904 & - & 3.222210 & 1.259745 \\
E & 1.783454 & 3.278179 & 0.049306 & 3.222210 & - & 4.481955 \\
F & 6.265409 & 7.760134 & 4.432649 & 1.259745 & 4.481955 & - \\
\multicolumn{7}{r}{ Kruskal-Wallis test: H (5, N = 900) $=86.38499, p=0.0000$} \\
\end{tabular}

Table 7. Multiple comparisons $p$-values (2-tailed) of area values for point variable.

\begin{tabular}{ccccccc}
\hline \multirow{2}{*}{ Dependent Area } & A & B & C & D & E & F \\
& R: $\mathbf{5 1 7 . 5 0}$ & R: $\mathbf{5 6 2 . 3 7}$ & R: $\mathbf{4 6 2 . 4 9}$ & R: $\mathbf{3 6 7 . 2 5}$ & R: $\mathbf{4 6 3 . 9 7}$ & R: $\mathbf{3 2 9 . 4 3}$ \\
\hline A & - & 1.000000 & 1.000000 & 0.000008 & 1.000000 & 0.000000 \\
B & 1.000000 & - & 0.013145 & 0.000000 & 0.015672 & 0.000000 \\
C & 1.000000 & 0.013145 & - & 0.022638 & 1.000000 & 0.000140 \\
D & 0.000008 & 0.000000 & 0.022638 & - & 0.019081 & 1.000000 \\
E & 1.000000 & 0.015672 & 1.000000 & 0.019081 & - & 0.000111 \\
F & 0.000000 & 0.000000 & 0.000140 & 1.000000 & 0.000111 & - \\
\multicolumn{7}{c}{ Independent (grouping) variable: Point } \\
\hline
\end{tabular}

Table 8. Multiple comparisons $z^{\prime}$-values of length values for point variable.

\begin{tabular}{ccccccc}
\hline \multirow{2}{*}{ Dependent Length } & $\mathbf{A}$ & $\mathbf{B}$ & $\mathbf{C}$ & $\mathbf{D}$ & $\mathbf{E}$ & $\mathbf{F}$ \\
& $\mathbf{R}: \mathbf{4 9 4 . 1 5}$ & $\mathbf{R}: \mathbf{5 4 5 . 8 5}$ & $\mathbf{R : ~} \mathbf{4 5 6 . 5 1}$ & $\mathbf{R : ~} \mathbf{4 0 2 . 4 9}$ & $\mathbf{R : ~} \mathbf{4 4 3 . 1 5}$ & R: $\mathbf{3 6 0 . 8 5}$ \\
\hline $\mathrm{A}$ & - & 1.722488 & 1.253748 & 3.053415 & 1.698945 & 4.440867 \\
$\mathrm{~B}$ & 1.722488 & - & 2.976236 & 4.775903 & 3.421433 & 6.163355 \\
$\mathrm{C}$ & 1.253748 & 2.976236 & - & 1.799667 & 0.445197 & 3.187119 \\
$\mathrm{D}$ & 3.053415 & 4.775903 & 1.799667 & - & 1.354470 & 1.387452 \\
$\mathrm{E}$ & 1.698945 & 3.421433 & 0.445197 & 1.354470 & - & 2.741922 \\
$\mathrm{~F}$ & 4.440867 & 6.163355 & 3.187119 & 1.387452 & 2.741922 & - \\
& \multicolumn{2}{c}{ Independent (grouping) variable: Point } \\
\end{tabular}

Table 9. Multiple comparisons $p$-values (2-tailed) of length values for point variable.

\begin{tabular}{|c|c|c|c|c|c|c|}
\hline Dependent Length & $\begin{array}{c}\text { A } \\
\text { R: } 494.15\end{array}$ & $\begin{array}{c}\text { B } \\
\text { R: } 545.85\end{array}$ & $\begin{array}{c}C \\
R: 456.51\end{array}$ & $\begin{array}{c}\text { D } \\
\text { R: } 402.49\end{array}$ & $\begin{array}{c}\text { E } \\
\text { R: } 443.15\end{array}$ & $\begin{array}{c}F \\
R: 360.85\end{array}$ \\
\hline A & - & 1.000000 & 1.000000 & 0.033938 & 1.000000 & 0.000134 \\
\hline B & 1.000000 & - & 0.043772 & 0.000027 & 0.009344 & 0.000000 \\
\hline $\mathrm{C}$ & 1.000000 & 0.043772 & - & 1.000000 & 1.000000 & 0.021555 \\
\hline D & 0.033938 & 0.000027 & 1.000000 & - & 1.000000 & 1.000000 \\
\hline E & 1.000000 & 0.009344 & 1.000000 & 1.000000 & - & 0.091621 \\
\hline $\mathrm{F}$ & 0.000134 & 0.000000 & 0.021555 & 1.000000 & 0.091621 & - \\
\hline \multicolumn{7}{|c|}{$\begin{array}{l}\text { Independent (grouping) variable: Point } \\
\text { uskal-Wallis test: } \mathrm{H}(5, \mathrm{~N}=900)=47.56759, p=0.0000\end{array}$} \\
\hline
\end{tabular}


On the basis of multiple comparisons and the set significance level of 0.05 it was proved that there is significant difference in areas mainly between points $\mathrm{A}$ and $\mathrm{F}$, which was obvious from the previous testing.

Further, there is a significant difference primarily between B and F, B and D. It is also evident that there are significant differences in areas between points on the front and their opposite on the rear side of briquettes, i.e., between point $\mathrm{A}$ and its opposite on the other side of the briquette, point $\mathrm{D}$. The same observation goes for the pair points $\mathrm{B}$ and $\mathrm{E}, \mathrm{C}$ and $\mathrm{F}$.

In the case of the length variable, there is significant difference in particle length mainly between points $B$ and $F$, and also between $B$ and $D$. It is also evident that there is no significant difference between points on the front side (i.e., $\mathrm{A}$ and $\mathrm{B}, \mathrm{B}$ and $\mathrm{C}, \mathrm{C}$ and $\mathrm{A}$ ) as well as points on the rear side (that is, D and E, E and F, D and F).

It can be concluded that PSD on the briquette cross-section surface is not uniform; there are differences between the particle sizes in terms of the length and area on the briquette surface. Generally, the largest particles are on the front side, while the particles with smaller dimensions are on the rear side.

\section{Discussion}

As stated before, the size of the particles significantly affects the physical and mechanical properties as well as burning characteristics of briquettes $[4,10,11,17,18,22]$. Particle size and PSD have a great impact on the compressibility of a bulk input material and the durability of the final briquettes $[8,11,22,61]$. Usually, with the smaller particle size, the density, mechanical strength, hardness, mechanical durability, impact resistance and the burning time of densified briquettes are increased $[4,6,15,20-22]$, however very fine grinding is undesirable due to the increased cost of briquette production [11] and the longer fuel ignition time [23].

Since it is known that the particle distribution is not uniform, that the larger particles agglomerate in the middle, and the smaller on the bottom of briquettes, mixing of the material during the densification could decrease this non-uniformity in the distribution of larger and smaller particles, which could lead to an increase in the quantity of contact points for inter-bonding among particles, and thus, to higher mechanical strength and lower abrasion of the final products during handling and transportation.

\section{Conclusions}

On the basis of image-based macroscopic analysis, the surface structure of hemp, miscanthus and pine sawdust briquettes was analysed and assessed. The size of the particle, that is, their length and area and their distributions on the briquette surface were determined. Based on the Kruskal-Wallis test a statistically significant difference (with 99\% confidence) in the length and area of particles within specified locations on the briquette surface, has been demonstrated. It was proved that the particles with largest lengths are situated at point $B$, i.e., in the middle of the front side, followed by points $A$ on the top of the briquette, point $C$ on the bottom of the briquette, followed by points on the rear side in the same order, E, D, and F. In the case of area values, the results were analogous, the front side showed the same results, i.e., the largest particles in terms of area are located at the $\mathrm{B}, \mathrm{A}$, and $\mathrm{C}$ points. On the rear side, the order of points with the largest particle areas was D, E, and F. For all the briquettes, made from three biomass sources and produced under the same conditions, the smallest particles are situated at the bottom of the briquette, whereas the largest are located in the middle of the briquette cross section. To conclude, the behavioural patterns of selected input materials during the agglomeration process in the pressing chamber of the briquetting machine as well as particle sizes at different locations on the briquette surface were identified and thus contributed to a better understanding of the densification and agglomeration processes. 
Acknowledgments: This research was supported by the Internal Grant Agency of the Faculty of Tropical AgriSciences, Czech University of Life Sciences, Prague [grant number 20165012 and 20175011]. Acknowledgements also go to Ing. Anna Korbářová, Ph.D. from the University of Chemistry and Technology Prague for the first professional acquaintance with image analysis and to Ing. Jindřich Karanský, Ph.D. for language help.

Author Contributions: Veronika Chaloupková contributed to experiment design, performed the experiments, collected and analyzed the data and wrote the paper. Tatiana Ivanova conceived and designed the experiments, provided the biomass, contributed to the paper writing and reviewed the manuscript. Ondřej Ekrt provided microscope facilities and professional supervision of image analysis. Abraham Kabutey contributed to data analysis and David Herák revised the manuscript.

Conflicts of Interest: The authors declare no conflicts of interest.

\section{References}

1. Alaru, M.; Kukk, L.; Olt, J.; Menind, A.; Lauk, R.; Vollmer, E.; Astover, A. Lignin content and briquette quality of different fibre hemp plant types and energy sunflower. Field Crop. Res. 2011, 124, 332-339. [CrossRef]

2. Carels, N. The Challenge of Bioenergies: An Overview. In Biofuel's Engineering Process Technology; dos Santos Bernardes, M.A., Ed.; InTech: Rijeka, Croatia, 2011; pp. 23-64. ISBN 978-953-307-480-1.

3. Vaezi, M.; Pandey, V.; Kumar, A.; Bhattacharyya, S. Lignocellulosic biomass particle shape and size distribution analysis using digital image processing for pipeline hydro-transportation. Biosyst. Eng. 2013, 144, 97-112. [CrossRef]

4. Zhang, J.; Guo, Y. Physical properties of solid fuel briquettes made from Caragana korshinskii Kom. Powder Technol. 2014, 256, 293-299. [CrossRef]

5. Portugal-Pereira, J.; Nakatani, J.; Kurisu, K.; Hanaki, K. Life cycle assessment of conventional and optimised Jatropha biodiesel fuels. Renew. Energy 2016, 86, 585-593. [CrossRef]

6. Ndindeng, S.A.; Mbassi, J.E.G.; Mbacham, W.F.; Manful, J.; Graham-Acquaah, S.; Moreira, J.; Dossou, J.; Futakuchi, K. Quality optimization in briquettes made from rice milling by-products. Energy Sustain. Dev. 2015, 29, 24-31. [CrossRef]

7. Ramírez-Gómez, A.; Gallego, E.; Fuentes, J.M.; Gonzáles-Montellano, C.; Ayuga, F. Values for particle-scale properties of biomass briquettes made from agroforestry residues. Particuology 2014, 12, 100-106. [CrossRef]

8. Hoover, A.N.; Tumuluru, J.S.; Teymouri, F.; Moore, J.; Gresham, G. Effect of pelleting process variables on physical properties and sugar yields of ammonia fiber expansion pretreated corn stover. Bioresour. Technol. 2014, 164, 128-135. [CrossRef] [PubMed]

9. Kaliyan, N.; Morey, R.V. Natural binders and solid bridge type binding mechanisms in briquettes and pellets made from corn stover and switchgrass. Bioresour. Technol. 2010, 101, 1082-1090. [CrossRef] [PubMed]

10. Karunanithy, C.; Wang, Y.; Muthukumarappan, K.; Pugalendhi, S. Physiochemical Characterization of Briquettes Made from Different Feedstock. Biotechnol. Res. Int. 2012, 2012, 1-12. [CrossRef] [PubMed]

11. Kaliyan, N.; Morey, R.V. Factors affecting strength and durability of densified biomass products. Biomass Bioenergy 2009, 33, 337-358. [CrossRef]

12. Pietsch, W. Agglomeration Processes: Phenomena, Technologies, Equipment; John Wiley \& Sons: New York, NY, USA, 2008; pp. 29-300. ISBN 9783527303694.

13. Stelte, W.; Holm, J.K.; Sanadi, A.R.; Barsberg, S.; Ahrenfeldt, J.; Henriksen, U.B. A study of bonding and failure mechanisms in fuel pellets from different biomass resources. Biomass Bioenergy 2011, 35, 910-918. [CrossRef]

14. Antwi-Boasiako, C.; Acheampong, B.B. Strength properties and calorific values of sawdust-briquettes as wood-residue energy generation source from tropical hardwoods of different densities. Biomass Bioenergy 2016, 85, 144-152. [CrossRef]

15. Missagia, B.; Guerrero, C.; Narra, S.; Sun, Y.; Ay, P.; Krautz, H.J. Physicomechanical properties of rice husk pellets for energy generation. Energy Fuels 2011, 25, 5786-5790. [CrossRef]

16. Febbi, P.; Menesatti, P.; Costa, C.; Pari, L.; Cecchini, M. Automated determination of poplar chip size distribution based on combined image and multivariate analyses. Biomass Bioenergy 2015, 73, 1-10. [CrossRef]

17. Tumuluru, J.S.; Wright, C.T.; Hess, J.R.; Kenney, K.L. A review of biomass densification systems to develop uniform feedstock commodities for bioenergy application. Biofuels Bioprod. Bioref. 2011, 5, 683-707. [CrossRef]

18. Guo, Q.; Xueli, C.; Haifeng, L. Experimental research on shape and size distribution of biomass particle. Fuel 2012, 94, 551-555. [CrossRef] 
19. Mani, S.; Tabil, L.G.; Sokhansanj, S. Effects of compressive force, particle size and moisture content on mechanical properties of biomass pellets from grasses. Biomass Bioenergy 2006, 30, 648-654. [CrossRef]

20. Mitchual, S.J.; Mensah, K.F.; Darkwa, N.A. Effect of species, particle size and compacting pressure on relaxed density and compressive strength of fuel briquettes. Int. J. Energy Environ. Eng. 2013, 4-30. [CrossRef]

21. Harun, N.Y.; Afzal, M.T. Effect of Particle Size on Mechanical Properties of Pellets Made from Biomass Blends. Procedia Eng. 2016, 148, 93-99. [CrossRef]

22. Sutrisno, T.; Anggono, W.; Suprianto, F.D.; Siahaan, I.H. The Effects of Particle Size and Pressure on the Combustion characteristics of Cerbera Manghasleaf Briquettes. ARPN J. Eng. Appl. Sci. 2017, 12, 931-936.

23. Davies, R.M.; Abolude, D.S. Ignition and Burning Rate of Water Hyacinth Briquettes. J. Sci. Res. Rep. 2013, 2, 111-120. [CrossRef] [PubMed]

24. Saptoadi, H. The Best Biobriquette Dimension and Its Particle Size. Asian J. Energy Environ. 2008, 9, 161-175.

25. Tembe, E.T.; Azeh, E.; Ekhuemelo, D.O. Effect of Particle Size on Quality of Briquettes Produced from Sawdust of Daniella oliveiri and Gmelina arborea in Makurdi, Benue State, Nigeria. Asian Res. J. Agric. 2017, 3, 1-7. [CrossRef]

26. Huko, D.; Kamau, D.N.; Ogola, W.O. Effects of Varying Particle Size on Mechanical and Combustion Characteristics of Mango Seed Shell Cashew Nut Shell Composite Briquettes. Int. J. Eng. Sci. Invent. 2015, 4, 32-39. [CrossRef]

27. DeCost, B.L.; Holm, E.A. A computer vision approach for automated analysis and classification of microstructural image data. Comput. Mater. Sci. 2015, 110, 126-133. [CrossRef]

28. Seo, J.O.; Han, S.U.; Lee, S.H.; Kim, H. Computer vision techniques for construction safety and health monitoring. Adv. Eng. Inform. 2015, 29, 239-251. [CrossRef]

29. Zhu, Y.; Cao, Z.; Lu, H.; Li, Y.; Xiao, Y. In-field automatic observation of wheat heading stage using computer vision. Biosyst. Eng. 2016, 143, 28-41. [CrossRef]

30. Calvo, H.; Moreno-Armendáriz, M.A.; Godoy-Calderón, S. A practical framework for automatic food products classification using computer vision and inductive characterization. Neurocomputing 2016, 175, 911-923. [CrossRef]

31. Cubero, S.; Diago, M.P.; Blasco, J.; Tardáguila, J.; Millán, B.; Aleixos, N. A new method for pedicel/peduncle detection and size assessment of grapevine berries and other fruits by image analysis. Biosyst. Eng. 2014, 117, 62-72. [CrossRef]

32. Girolami, A.; Napolitano, F.; Faraone, D.; Braghieri, A. Measurement of meat color using a computer vision system. Meat Sci. 2013, 93, 111-118. [CrossRef] [PubMed]

33. Morais de Oliveira, E.; Leme, D.S.; Barbosa Groenner, B.H.; Rodarte Mirian, P.; Fonseca Alvarenga Pereira, R.G. A computer vision system for coffee beans classification based on computational intelligence techniques. J. Food Eng. 2015, 171, 22-27. [CrossRef]

34. Pace, B.; Cavallo, D.P.; Cefola, M.; Colella, R.; Attolico, G. Adaptive self-configuring computer vision system for quality evaluation of fresh-cut radicchio. Innov. Food Sci. Emerg. Technol. 2015, 32, 200-207. [CrossRef]

35. Berghel, J.; Frodeson, S.; Granström, K.; Renström, R.; Ståhl, M.; Nordgren, D.; Tomani, P. The effects of kraft lignin additives on wood fuel pellet quality, energy use and shelf life. Fuel Process. Technol. 2013, 112, 64-69. [CrossRef]

36. Lihong, L.; Qingbin, A. An in-depth study of tool wear monitoring technique based on image segmentation and texture analysis. Measurement 2016, 79, 44-52. [CrossRef]

37. Song, Y.; Glasbey, C.A.; Horgan, G.W.; Polder, G.; Dieleman, J.A.; van der Heijden, G.W.A.M. Automatic fruit recognition and counting from multiple images. Biosyst. Eng. 2014, 118, 203-215. [CrossRef]

38. Niwa, M.; Hiraishi, Y. Quantitative analysis of visible surface defect risk in tablets during film coating using terahertz pulsed imaging. Int. J. Pharmaceut. 2014, 461, 342-350. [CrossRef] [PubMed]

39. Wu, L.; He, J.; Liu, G.; Wang, S.; He, X. Detection of common defects on jujube using Vis-NIR and NIR hyperspectral imaging. Postharvest Biol. Technol. 2016, 116, 134-142. [CrossRef]

40. González, Á.; Bergasa, L.M. A text reading algorithm for natural images. Image Vis. Comput. 2013, 31, 255-274. [CrossRef]

41. Wang, W. Image analysis of particles by modified Ferret method-Best-fit rectangle. Powder Technol. 2006, 165, 1-10. [CrossRef] 
42. Igathinathane, C.; Melin, S.; Sokhansanj, S.; Bi, X.; Lim, C.J.; Pordesimo, L.O.; Columbus, E.P. Machine vision based particle size and size distribution determination of airborne dust particles of wood and bark pellets. Powder Technol. 2009, 196, 202-212. [CrossRef]

43. Igathinathane, C.; Pordesimo, L.O.; Columbus, E.P.; Batchelor, W.D.; Sokhansanj, S. Sieveless particle size distribution analysis of particulate materials through computer vision. Comput. Electron. Agric. 2009, 66, 147-158. [CrossRef]

44. Souza, D.O.C.; Menegalli, F.C. Image analysis: Statistical study of particle size distribution and shape characterization. Powder Technol. 2011, 214, 57-63. [CrossRef]

45. Kumara, G.H.A.J.J.; Hayano, K.; Ogiwara, K. Image Analysis Technique on Evaluation of Particle Size Distribution of Gravel. Int. J. Geomate 2012, 3, 290-297. [CrossRef]

46. Gil, M.; Teruel, E.; Arauzo, I. Analysis of standard sieving method for milled biomass through image processing. Effects of particle shape and size for poplar and corn stover. Fuel 2014, 116, 328-340. [CrossRef]

47. Pothula, A.K.; Igathinathane, C.; Kronberg, S.; Hendrickson, J. Digital image processing based identification of nodes and internodes of chopped biomass stems. Comput. Electron. Agr. 2014, 105, 54-65. [CrossRef]

48. Pons, M.-N.; Dodds, J. Chapter Fifteen-Particle Shape Characterization by Image Analysis. Prog. Filt. Sep. 2015, 609-636. [CrossRef]

49. Ozen, M.; Guler, G. Assessment of optimum threshold and particle shape parameter for the image analysis of aggregate size distribution of concrete sections. Opt. Lasers Eng. 2014, 53, 122-132. [CrossRef]

50. Yang, Z.; Peng, X.-F.; Lee, D.-J.; Chen, M.-Y. An image-based method for obtaining pore-size distribution of porous media. Environ. Sci. Technol. 2009, 43, 3248-3253. [CrossRef] [PubMed]

51. Shah, S.G.; Kishen, J.M.C. Fracture properties of concrete-concrete interfaces using digital image correlation. Exp. Mech. 2011, 51, 303-313. [CrossRef]

52. Berrezueta, E.; González-Menéndez, L.; Ordóñez-Casado, B.; Olaya, P. Pore network quantification of sandstones under experimental $\mathrm{CO}_{2}$ injection using image analysis. Comput. Geosci. 2015, 77, 97-110. [CrossRef]

53. Muntean, A.; Ivanova, T.; Havrland, B.; Pobedinsky, V.; Vrancean, V. Particularities of Bio-Raw Material Particle Agglomeration during Solid Fuel Pressing Process. In Proceedings of the Engineering for Rural Development, Jelgava, Latvia, 23-24 May 2013; pp. 499-503.

54. Xue, S.; Lewandowski, I.; Wang, X.; Yi, Z. Assessment of the production potentials of Miscanthus on marginal land in China. Renew. Sust. Energy Rev. 2016, 54, 932-943. [CrossRef]

55. Papadopoulou, E.; Bikiaris, D.; Chrysafis, K.; Wladyka-Przybylak, M.; Wesolek, D.; Mankowski, J.; Kolodziej, J.; Baraniecki, P.; Bujnowicz, K.; Gronberg, V. Value-added industrial products from bast fiber crops. Ind. Crops Prod. 2015, 68, 116-125. [CrossRef]

56. McKendry, P. Energy production from biomass (part 1): Overview of biomass. Bioresour. Technol. 2002, 88, 37-46. [CrossRef]

57. CSN EN 15149-1 (838219). Solid biofuels-Determination of particle size distribution. In Part 1, Oscillating Screen Method Using Sieve Apertures of $1 \mathrm{~mm}$ and Above; Czech Office for Standards, Metrology and Testing: Prague, Czech Republic, 2011; 16p.

58. Womac, A.R.; Igathinathane, C.; Bitra, P.; Miu, P.; Yang, T.; Sokhansanj, S.; Narayan, S. Biomass pre-processing size reduction with instrumented mills. In Proceedings of the 2007 ASAE Annual Meeting. American Society of Agricultural and Biological Engineers, Minneapolis, MN, USA, 17-20 June 2007; pp. 1-15.

59. Briklis. Briquetting Presses BrikStar CS 20, 50. Available online: http://www.briklis.cz/en/briquettingpresses-for-wood/brikstar-cs-25-50/ (accessed on 3 December 2015).

60. Taylor, S. Business Statistics for Non-Mathematicians, 2nd ed.; Palgrave MacMillan: London, UK, 2007; pp. 123-185. ISBN 9780230206854.

61. Genasen, V.; Rosentrater, K.A.; Muthukumarappan, K. Flowability and handling characteristics of bulk solids and powders-A review with implication for DDGS. Biosyst. Eng. 2008, 101, 425-435. [CrossRef]

(C) 2018 by the authors. Licensee MDPI, Basel, Switzerland. This article is an open access article distributed under the terms and conditions of the Creative Commons Attribution (CC BY) license (http:/ / creativecommons.org/licenses/by/4.0/). 